\title{
Diagnóstico precoce da hepatite $C$ pela atenção primária à saúde
}

Early diagnosis of hepatitis $\mathrm{C}$ by primary health care

\section{Diagnóstico precoz de la hepatitis C por parte de la atención primaria a la salud}

Recebido: $17 / 01 / 2020$

Aprovado: 04/09/2020

Publicado: 03/03/2021
Geisa Perez Medina Gomide ${ }^{1}$

Rodrigo Juliano Molina ${ }^{2}$

Gilberto Araújo Pereira ${ }^{3}$

Cristina Cunha Hueb Barata Oliveira ${ }^{4}$

Trata-se de um estudo exploratório, descritivo, transversal, retrospectivo, de abordagem epidemiológica, realizado nas unidades de atenção primária à saúde de Uberaba entre 2014 e março de 2017, com objetivo de conhecer a prevalência e positividade do anticorpo Anti-hepatite C na população adulta acima de 40 anos. Foram testadas 17.845 pessoas através do teste de imunocromatográficos e, depois, aos 131 positivos aplicou-se o teste de genotipagem e estadiamento da fibrose hepática. Encontrou-se 0,73\% de positivos, sendo 79,3\% nascidos nas décadas de 1950 a 1970; e 24\% apresentavam fibrose hepática moderada, avançada ou cirrose. As formas de transmissão mais citadas foram uso de drogas (qualquer via); múltiplos parceiros sexuais e transfusões, hemodiálise ou transplante de órgãos. É importante capacitar os profissionais da rede de atenção primária sobre a importância da hepatite $C$, de seu diagnóstico precoce e dos grupos de risco prioritários, além de propiciar a ampliação do acesso ao diagnóstico.

Descritores: Atenção primária à saúde; Hepatite C; Prevalência; Epidemiologia; Diagnóstico precoce.

This is an exploratory, descriptive, cross-sectional, retrospective study with an epidemiological approach, carried out in primary health care units in the city of Uberaba between 2014 and March of 2017. It aimed to know the prevalence and positivity of the Anti-hepatitis $\mathrm{C}$ antibody in adult population over 40 years. 17,845 people were tested using the immunochromatographic test and then the 131 positives were tested for genotyping and liver fibrosis staging. It was found $0.73 \%$ of positives, $79.3 \%$ of whom were born in the 1950 s to 1970 s; and $24 \%$ had moderate liver fibrosis, advanced liver fibrosis or cirrhosis. The most cited forms of transmission were drug use (any route); multiple sexual partners and transfusions, hemodialysis or organ transplantation. It is important to train professionals in the primary care network on the importance of hepatitis $\mathrm{C}$, its early diagnosis and priority risk groups, in addition to providing greater access to diagnosis.

Descriptors: Primary health care; Hepatitis C; Prevalence; Epidemiology; Early diagnosis.

Se trata de un estudio exploratorio, descriptivo, transversal, retrospectivo, con enfoque epidemiológico, realizado en las unidades de atención primaria a la salud de Uberaba entre 2014 y marzo de 2017, con el objetivo de conocer la prevalencia y positividad del anticuerpo contra el virus hepatitis C en la población adulta mayor de 40 años. Un total de 17.845 personas se sometieron a la prueba inmunocromatográfica, y después se aplicó una prueba de genotipado y estadificación de la fibrosis hepática a los 131 positivos. Se encontró 0,73\% positivos, de los cuales 79,3\% nacieron entre los años 1950 y 1970; y el 24\% tenían fibrosis hepática moderada, avanzada o cirrosis. Las formas de transmisión más citadas fueron el consumo de drogas (por cualquier vía); las parejas sexuales múltiples y las transfusiones, la hemodiálisis o el trasplante de órganos. Es importante formar a los profesionales de la red de atención primaria sobre la importancia de la hepatitis $\mathrm{C}$, su diagnóstico precoz y los grupos de riesgo prioritarios, así como aumentar el acceso al diagnóstico. Descriptores: Atención primaria de salud; Hepatitis C; Prevalencia; Epidemiología; Diagnóstico precoz.

1. Médica. Especialista em Gastroenterologia e Hepatologia. Mestre em Medicina Tropical e Infectologia. Coordenadora do Centro de Referência em Hepatites Virais na Macrorregião Triângulo Sul do Estado de Minas Gerais. Hospital de Clínicas da Universidade Federal do Triângulo Mineiro (HCUFTM), Uberaba, MG, Brasil. ORCID: 0000-0002-6657-5515 E-mail: geisa.gomide@ebserh.gov.br

2. Médico. Especialista em Infectologia. Mestre em Medicina Tropical e Infectologia. Doutorando em Medicina Tropical e Infectologia e Professor Assistente do curso de graduação em Medicina da UFTM, Uberaba, MG, Brasil. ORCID: 0000-0003-2022-2068 E-mail: rodrigomollina@uol.com.br

3. Estatístico. Mestre em Ciências da Computação. Doutor em Estatística. Professor Adjunto do curso de graduação em Enfermagem da UFTM, Uberaba, MG, Brasil. ORCID: 0000-0002-9149-6368 E-mail: gilberto.pereira@ebserh.gov.br

4. Médica. Especialista em Medicina do Trabalho. Mestre em Infectologia e Medicina Tropical. Doutora em Infectologia. Professora Associada do curso de graduação em Medicina e da Pós Graduação em Medicina Tropical e Infectologia da UFTM, Uberaba, MG, Brasil. ORCID: 0000-0002-2558-2102 E-mail: chuebbarata@gmail.com 


\section{INTRODUÇÃO}

$\mathbf{E}$

stima-se que cerca de 70 milhões de pessoas estejam infectadas pelo vírus da hepatite $C$ (HCV) no mundo, o que hoje é considerado um problema global de saúde pública pela Organização Mundial de Saúde (OMS) ${ }^{1}$.

A hepatite pelo vírus $C$ é uma doença curável, mas pouco diagnosticada. Está associada a várias manifestações hepáticas e extra-hepáticas, incluindo tumores malignos ${ }^{2,3}$. Evolui para hepatite crônica em 55 a 85\% dos casos, dos quais 30\% desenvolvem cirrose hepática em cerca de 20 anos, e 2 a 4\% ao ano destes evoluem para carcinoma hepatocelular. A história natural do HCV é afetada por vários fatores demográficos, virológicos, clínicos e de estilo de vida. É importante compreender os determinantes do impacto do vírus para planejar estratégias apropriadas para detecção, prognóstico e tratamento ${ }^{4}$.

Metas internacionais foram estabelecidas para a eliminação da hepatite viral como ameaça à saúde pública até o ano de 2030, ressaltando a necessidade urgente de melhorar a busca de casos. A necessidade de aumentar o diagnóstico de HCV também se tornou mais pertinente como resultado da crescente disponibilidade e sucesso do tratamento antiviral de ação direta.

Globalmente, apenas 15 a 20\% dos indivíduos com infecção crônica por HCV são atualmente considerados conscientes de seu diagnóstico, e menos ainda recebem tratamento ${ }^{5}$. Mediante essas circunstâncias, a OMS, através do Global Health Sector Strategy on Viral Hepatitis 2016-2021: Towards Ending Viral Hepatitis, estabelece ser crucial desenvolver um forte sistema de informação estratégica para entender as epidemias de hepatite viral e desenvolver resposta eficaz ${ }^{6}$.

Em 2012, os Centros de Controle e Prevenção de Doenças dos Estados Unidos recomendaram o uso de testes para todos os indivíduos nascidos entre 1945 e 1965 (baby boomers), pois cerca de três quartos das infecções por HCV foram identificadas nesta faixa etária pela Pesquisa Nacional de Saúde e Nutrição (NHANES)7,8.

Em 2019, o Ministério da Saúde (MS) publicou o Plano para Eliminação da Hepatite C no Brasil, que visa ampliar o acesso à prevenção, diagnóstico e tratamento da hepatite $\mathrm{C}$, com a participação das três esferas de governo, para a redução de novas infecções e de mortalidade. Foram ainda definidos: o desenvolvimento de ações de comunicação e educação em saúde que promovam o diagnóstico na população acima de 40 anos de idade e grupos prioritários; a construção de linha de cuidado para as hepatites virais e o fortalecimento da vigilância epidemiológica9.

O MS propõe o aumento no número de pessoas testadas, priorizando grupos de acordo com sua vulnerabilidade, por exemplo: pessoas vivendo com HIV/AIDS, privados de liberdade, usuários de drogas, pessoas com múltiplos parceiros sexuais e aqueles em terapia renal substitutiva, entre outros, devem ser testados pelo menos uma vez ao ano. Já às pessoas com 40 anos ou mais, que possuem tatuagens e/ou piercings, expostos a material biológico e filhos de mãe portadora, recomenda-se testagem pelo menos uma vez na vida9 .

No Brasil, estudos mostram que o diagnóstico de HCV aumenta em prevalência a partir da quarta década de vida, e o diagnóstico é feito entre as idades de 46 e 60 anos em quase metade dos casos, com pico de prevalência na idade de 50-60 anos. Estudo de prevalência de base populacional, realizado nas capitais brasileiras entre 2005 e 2010, encontrou prevalência global de Anti-HCV de 1,38\% (IC 95\% 1,12\%-1,6\%) e, para a região Sudeste do país, a prevalência encontrada foi de 1,27\% $\%^{10-12}$.

Conforme os resultados do inquérito epidemiológico, o estado de Minas Gerais tem uma prevalência identificada de 2,47\% para a Macrorregião do Triângulo Sul ${ }^{13}$. Este resultado precisa ser questionado, visto que o próprio comportamento do agravo em âmbito nacional apresenta uma projeção de redução da incidência. Considerando a organização local dos serviços de saúde, a rede de assistência, a massa crítica e intelectual da região (centros 
formadores e faculdades médicas e de saúde), além da economia da região, o indicador encontrado é um aspecto a ser questionado.

Em investigação recente, 24.085 adultos residentes na Macrorregião do Triângulo Sul no estado de Minas Gerais foram testados para o anticorpo Anti-HCV, sendo encontrada prevalência de 0,76\%. A maioria dos indivíduos positivos eram nascidos entre 1951 e 1980, e os grupos de risco mais prevalentes foram aqueles que compartilhavam agulhas e seringas para uso de drogas e/ou medicamentos, estão ou já estiveram privado de liberdade e possuiam tatuagens ou piercings ${ }^{14}$.

Observa-se a existência de produções científicas que definem a prevalência do vírus em âmbito internacional e nacional. Entretanto, poucos estudos descrevem essa prevalência em localidades específicas. Esse conhecimento é aspecto crucial para o gerenciamento das ações, fortalecimento de iniciativas: rastreamento de casos, busca ativa, acompanhamento e inserção dos pacientes nos seguimentos adequados para o tratamento. Assim, este estudo tem como objetivo conhecer a prevalência e positividade do anticorpo Anti-hepatite $C$ na população adulta acima de 40 anos.

\section{MÉTODO}

Trata-se de um estudo exploratório, descritivo, transversal, retrospectivo, de abordagem epidemiológica.

Os dados analisados neste este estudo integram o Programa de Ampliação do Diagnóstico da Hepatite C do Ambulatório de Hepatites do Hospital de Clínicas da Universidade Federal do Triângulo Mineiro (HC-UFTM), em parceria com a Sociedade Brasileira de Hepatologia (SBH), realizado entre 2014 a março de 2017 com o intuito de rastrear os casos novos de Hepatite C no Município de Uberaba.

A proposta do programa, além do diagnóstico da Hepatite $C$, foi capacitar a rede de atenção à saúde para identificação dos grupos de risco. Os triagistas, integrantes das equipes da Atenção Primária, foram previamente treinados quanto à importância do diagnóstico precoce e complicações da doença, sobre a realização dos testes e preenchimento de ficha controle para positivos e negativos, incluindo o registro das perdas dos testes, bem como os dados sociodemográficos e epidemiológicos dos positivos, tais como década de nascimento, sexo e grupos de risco.

A idade mínima para participar da campanha foi 18 anos, sendo estimulados intencionalmente aqueles indivíduos com mais de 40 anos.

Os testes rápidos utilizados eram imunocromatográficos para detecção qualitativa de anticorpos específicos contra o HCV no soro, plasma ou sangue total humano (ALERE HCV ${ }^{\circledR}$ Código 02FK10); tendo sensibilidade de 100\% e especificidade de 99,4\%, segundo informações do fabricante.

Aos indivíduos que apresentaram teste positivo para Hepatite $C$, os agentes de saúde procediam o acolhimento e ofereciam o seguimento no Ambulatório de Hepatites do HC-UFTM com a equipe assistencial. Seguindo o Protocolo Clínico e Diretrizes Terapêuticas para Hepatite C e Coinfecções (PCDT) do MS implantados no serviço, para esses pacientes realizou-se pesquisa de biologia molecular (RNA-HCV quantitativo e genotipagem) para o vírus $\mathrm{C}$, além de estadiamento da fibrose hepática.

A pesquisa quantitativa do RNA-HCV foi realizada pelo Laboratório Macrorregional de Uberaba, vinculado à Secretaria Estadual de Saúde, é feita pelo método RT-PCR em tempo real, utilizando o kit Real Time $\mathrm{HCV}^{\circledR}$ do laboratório Abbott; e a genotipagem do vírus foi desenvolvida pelo Centro de Genomas, em convênio com a Secretaria Estadual de Saúde de Minas Gerais, feita pelo método RT-PCR em tempo real, utilizando o kit HCV Real Time Genotype II ${ }^{\circledR}$ do laboratório Abbott. 
Ainda dentro do PCDT, o estadiamento do grau da fibrose foi realizado para todos os pacientes infectados pelo HCV, coinfectados ou não pelo HIV, de modo a caracterizar ausência ou presença de doença avançada e definição da estratégia terapêutica. Este poderia ser realizado por qualquer um dos métodos disponíveis: APRI ou FIB4, biópsia hepática ou elastografia hepática ${ }^{16}$.

Segundo o IBGE, o local deste estudo, Uberaba, possui população estimada de 333.783 pessoas em 2019, com densidade demográfica em 2010 (último censo) de 65,43 hab $/ \mathrm{km}^{2}$. Em 2017, o salário médio mensal era de 2,6 salários mínimos. O PIB per capita em 2016 era de R\$ 41.360,17, 97,2\% de domicílios possuem esgotamento sanitário adequado, 90,7\% de domicílios urbanos em vias públicas com arborização e 31,5\% de domicílios urbanos em vias públicas com urbanização adequada (presença de bueiro, calçada, pavimentação e meio-fio) ${ }^{15}$. Para avaliar a prevalência geral de Hepatite $\mathrm{C}$, considerou-se as 17.845 pessoas testadas no referido período.

Quanto à distribuição por ano e perfil sociodemográfico e epidemiológico, foram considerados os casos positivos para Anti-HCV. Foram excluídos da análise testes duplicados, testes realizados em pessoas que não residiam na cidade e, ainda, aquelas informações relacionadas às pessoas que apresentaram resultados negativos para a testagem rápida de AntiHVC.

Foi utilizada análise estatística descritiva univariada a partir de frequências absolutas e percentuais e os resultados organizados em tabelas e gráficos. Os softwares Excel ${ }^{\circledR}$ e StatSoft. Inc. (2007) - STATISTICA foram utilizados.

O projeto foi aprovado pelo Comitê de Ética em Pesquisa da Universidade Federal do Triângulo Mineiro em conformidade com a resolução brasileira do Conselho Nacional de Saúde $\mathrm{n}^{\circ} 466 / 2012$ que trata de pesquisas em seres humanos, sob registro no CAAE $\mathrm{n}^{\circ}$ 68312717.5.0000.5154 e parecer de aprovação $n^{\circ} 2.394 .876$.

\section{RESULTADOS}

De acordo com dados do Programa de Ampliação do Diagnóstico da Hepatite C do Ambulatório de Hepatites do HC-UFTM em parceria com a SBH, realizado entre 2014 a março de 2017, foram distribuídos 400 testes rápidos para detecção de hepatite C para cada uma das 30 Unidades Básicas de Saúde (UBSs) existentes no Município no ano de 2014, totalizando 12.000 testes, quando as testagens tiveram início. Posteriormente, a Secretaria Municipal de Saúde e o HC-UFTM promoveram campanhas nas praças e calçadões, integrando a testagem para Hepatite C a outros eventos como Dia Mundial da Saúde, Semana da Saúde, Outubro Rosa, Novembro Azul, entre outras, totalizando 17.845 testes realizados (Figura 1).

Figura 1. Fluxograma da população testada, exclusões e amostra final no período de 2014 a 2017. Uberaba, Minas Gerais, 2020.

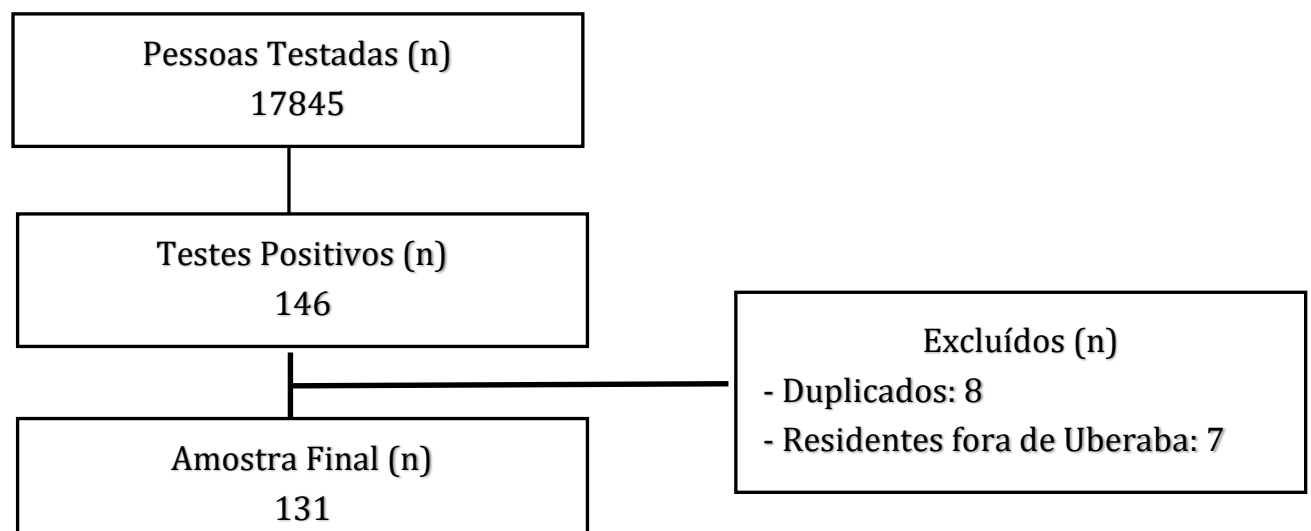


Para o seguimento da população alvo, os 131 casos positivos foram acolhidos pelas equipes previamente treinadas da Atenção Primária e encaminhados ao Ambulatório de Hepatites do HC-UFTM, sem fila de espera para marcação das consultas.

No ambulatório, esses pacientes eram orientados sobre a importância do diagnóstico ainda na fase assintomática, os riscos da ausência de acompanhamento médico e as possibilidades terapêuticas. Após anamnese e exame físico, eram solicitados os exames complementares recomendados pelo PCDT de 2012, atualizado em 2015, 2017, 2018 e 2019.0 paciente já saía da consulta com o retorno agendado, buscando reduzir o abandono de tratamento e tal informação era replicada à Diretoria de Atenção Básica do município. Assim, as faltas às consultas eram reduzidas.

O município de Uberaba é dividido em Distritos Sanitários I, II e III (Figura 2). Dos 17.845 testes realizados, 8.106 pessoas tiveram os endereços anotados, sendo identificado o distrito de moradia. Para o restante das pessoas testadas (9.739) não foi possível recuperar o endereço de residência. Dos 131 positivos, foi possível recuperar o endereço de 125 (Tabela 1).

Figura 2. Distritos sanitários de Uberaba/MG, Brasil. 2020.

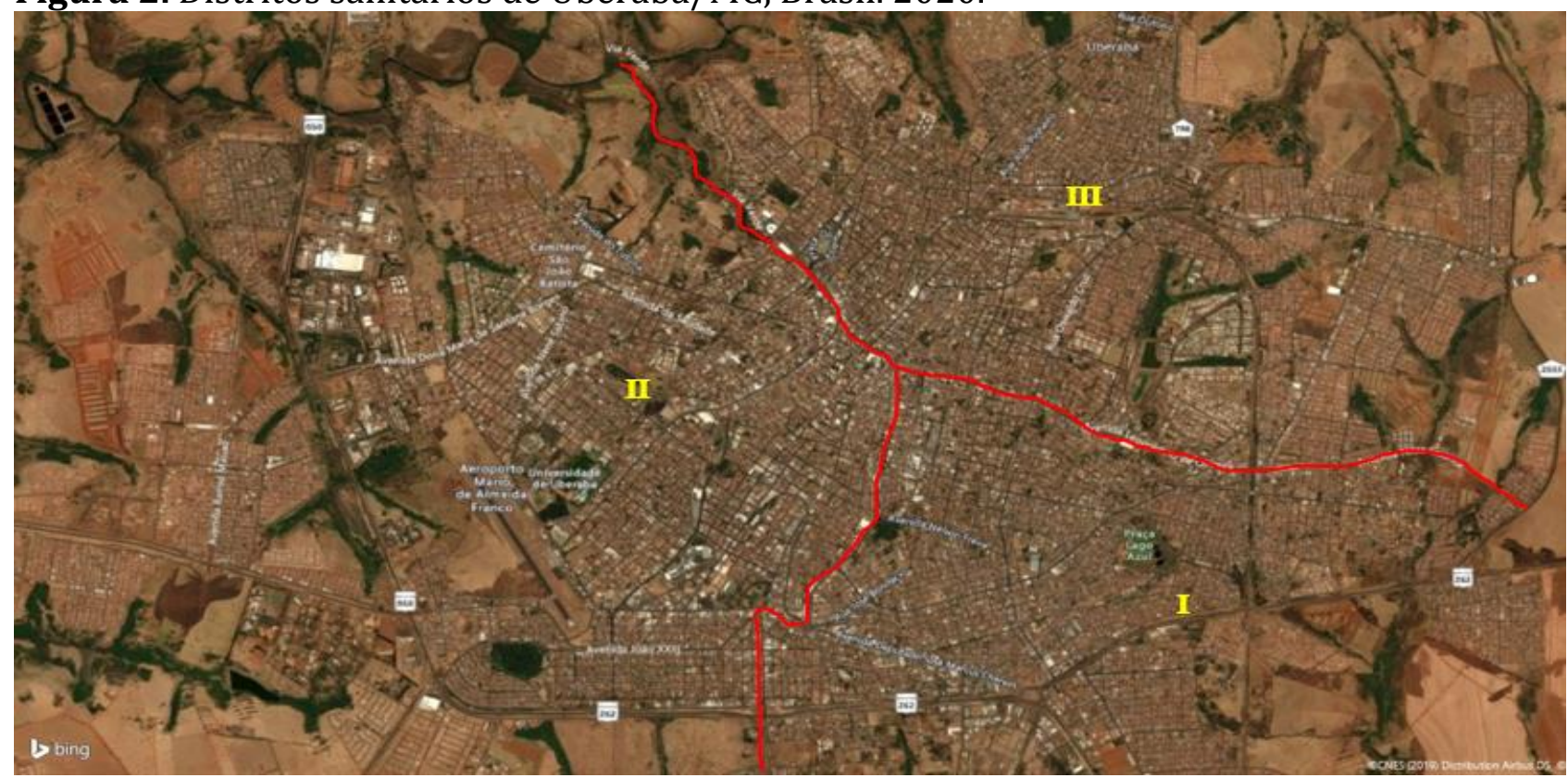

Fonte: POWER MAP. Legenda: I - Distrito Sanitário I; II - Distrito sanitário II; III - Distrito sanitário III.

Tabela 1. Prevalência de Anti-HCV reagente de acordo com o distrito de moradia. Uberaba, Minas Gerais, 2020.

\begin{tabular}{cccc}
\hline Distritos & Testes positivos (n) & Testes realizados (n) & $\begin{array}{c}\text { Prevalência no distrito } \\
\text { Sanitários }\end{array}$ \\
DS I Abadia & 62 & 2.738 & 2,26 \\
DS II Mercês & 28 & 3.183 & 0,87 \\
DS III Boa Vista & 35 & 2.185 & 1,60 \\
Sem endereço & 6 & 9.739 & 0,06 \\
Total & $\mathbf{1 3 1}$ & $\mathbf{1 7 . 8 4 5}$ & $\mathbf{0 , 7 3}$ \\
\hline
\end{tabular}

O presente estudo encontrou 0,73\% de Anti-HCV positivos em 17.845 pessoas testadas no município de Uberaba. Dentre os positivos, $62,6 \%$ eram homens e 79,3\% nasceram nas décadas de 50, 60 e 70 (Gráfico 1). Um quarto dos positivos para Anti-HCV apresentava fibrose moderada, avançada ou cirrose e 71,3\% eram portadores do genótipo 1 do vírus (Gráfico 2). 
Gráfico 1. Anti-HCV positivos de 2014 a março de 2017, segundo à década de nascimento, sexo. Uberaba, Minas Gerais, 2020.

Distribuição quanto às décadas de nascimento (\%)

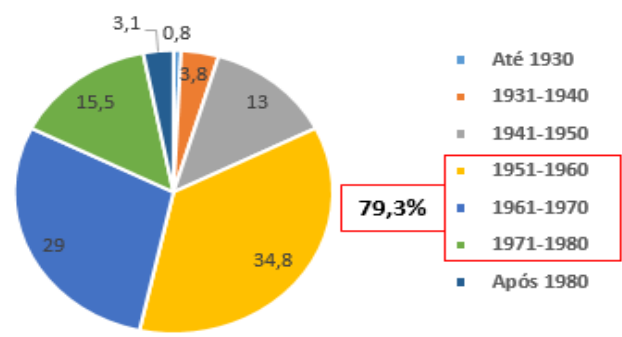

Distribuição quanto ao sexo (\%)

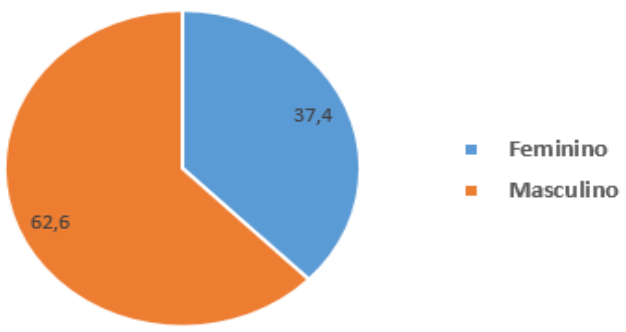

Gráfico 2. Anti-HCV positivos de 2014 a março de 2017, segundo ao genótipo do vírus $\mathrm{C}$ e ao estadiamento da fibrose. Uberaba, Minas Gerais, 2020.
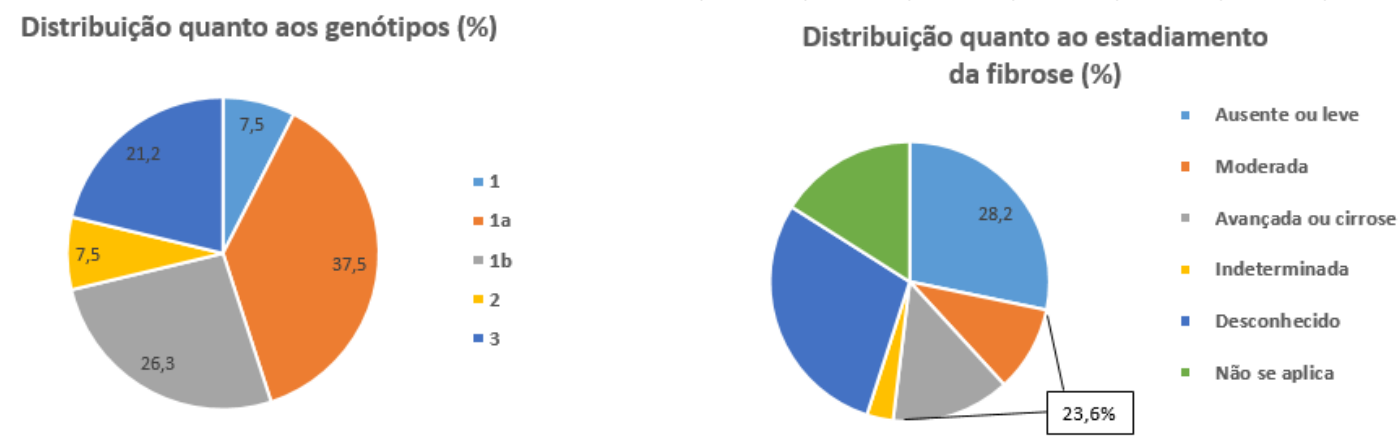

Com relação às formas de transmissão (grupos de risco), algumas pessoas apresentavam mais de uma possível forma de aquisição do vírus, enquanto outras não tiveram grupo de risco identificável (Tabela 2). As formas de transmissão mais citadas foram: 1) uso atual ou pregresso de drogas (por qualquer via); 2) múltiplos parceiros sexuais sem preservativo; 3) transfusão de sangue ou hemoderivados, hemodiálise ou transplante de órgãos (transmissão iatrogênica). Em menor número, os seguintes grupos de risco foram identificados: tatuagem ou piercings; cirurgias ou injeção com material não descartável; convivência com os vírus B e/ou HIV (Tabela 2).

Tabela 2. Formas de transmissão ou grupos de risco das pessoas positivas para o Anti-HCV de 2014 a março de 2017. Uberaba, Minas Gerais, 2020.

\begin{tabular}{lcc}
\hline Grupos de risco* & n & $\mathbf{( \% )}$ \\
\hline Usuários de drogas ilícitas & 24 & 18,32 \\
Múltiplos parceiros & 23 & 17,55 \\
Transfusão/Hemodálise ou Transplante & 20 & 15,26 \\
Tatuagem/piercing & 14 & 10,68 \\
Iatrogenia (seringas/cirurgias) & 10 & 7,63 \\
Convive c/ HIV e/ou HBV & 9 & 6,87 \\
Risco ocupacional & 6 & 4,58 \\
Familiar portador & 5 & 3,81 \\
Privado de liberdade & 3 & 2,29 \\
Mãe portadora & 2 & 1,52 \\
Morador de rua & 1 & 0,76 \\
Não identificado grupo de risco & 46 & 35,11 \\
\hline
\end{tabular}

* Algumas pessoas apresentavam mais de um grupo de risco, outras não tiveram grupo de risco identificável. 


\section{DISCUSSÃo}

Com a disponibilização pelo Ministério de Saúde (MS) dos antivirais de ação direta, medicamentos potentes e seguros para o tratamento da hepatite $\mathrm{C}$, o que tem trazido preocupação é o grande número de casos não diagnosticados. Estratégias para lidar com isso são necessárias e pesquisadores têm tentado encontrar a melhor custo-efetividade para diagnóstico, prevenção e erradicação da HCV no mundo.

No município de Uberaba, Minas Gerais, foram aplicadas as estratégias preconizadas pela OMS, depois contempladas no Plano para Eliminação da Hepatite C no Brasil do MS, que recomendam a capacitação da rede de atenção básica para diagnóstico do agravo ${ }^{6,9}$.

A prevalência do marcador sorológico de contato para a Hepatite C (Anti-HCV) aqui encontrada $(0,73 \%)$ vai de encontro ao estimado pelo MS em $2018(0,70 \%)$, diferindo de dados publicados anteriormente, extraídos de inquéritos sorológicos realizados no Brasil e no estado de Minas Gerais (1,27\% para Minas Gerais e 2,47\% para a macrorregião do Triângulo do Sul, respectivamente) ${ }^{12,13}$.

Em relação à faixa etária dos portadores de HCV identificados, observou-se que tais indivíduos nasceram em décadas semelhantes ao descrito em países como Suíça, EUA, Espanha e o próprio Brasil, onde identificou-se que os nascidos após a Segunda Guerra Mundial tiveram maior risco de exposição ao vírus ${ }^{17-20}$. Tal achado pode nortear as políticas públicas para erradicação do vírus $\mathrm{C}$ no município e mostra a importância da investigação diagnóstica nessas faixas etárias em todos os pontos da rede de atenção à saúde.

Quanto ao sexo, o Boletim Epidemiológico do MS, publicado em 2019, demonstra que a razão entre homens e mulheres vem caindo, tendo ficado em 1,2 no ano de 2018. 0 presente estudo encontrou razão de 1,7 com prevalência maior para os homens no município polo da Macrorregião do Triângulo Sul21.

A distribuição dos genótipos do vírus $C$ entre os positivos e que realizaram os exames de biologia molecular segue a mesma tendência publicada para o Brasil. 0 genótipo 1 é o mais prevalente na população brasileira, seguido dos genótipos 3 e 2. Nenhum genótipo 4 ou 5 foi encontrado 20 .

Quanto ao estadiamento da fibrose, estudo brasileiro publicado em 2014 demonstrou associação entre idade no diagnóstico e grau de lesão hepática na hepatite $C$, ou seja, quanto maior a idade, maior o grau de fibrose. 0 presente estudo mostrou que um quarto dos positivos para Anti-HCV já apresentava fibrose moderada ou grave. Sabendo-se que a Hepatite C é uma doença silenciosa, que os mais velhos têm maior risco de fibrose avançada ou cirrose e são os mesmos nos quais a prevalência é maior, tornam-se urgentes a ampliação do diagnóstico e as intervenções terapêuticas ${ }^{10}$.

Esta realidade exige preparo diferenciado de equipes de saúde e do sistema nos seus diferentes pontos de atenção, pois os serviços de saúde deverão estar preparados para a ascensão de complicações entre as populações infectadas, bem como para o manejo da epidemia e suas sequelas. Tal fato torna crucial a detecção dos casos entre a população em geral e identificação das pessoas que convivem com o vírus e não sabem.

0 presente estudo teve como principal foco as pessoas com mais de 40 anos, ou seja, nascidas até a década de 1980. Entretanto, em relação à provável forma de aquisição do vírus, as formas de transmissão mais citadas foram justamente aquelas para as quais o MS recomenda testagem anual, visto o grande potencial de transmissão, a saber: uso atual ou pregresso de drogas; múltiplos parceiros sexuais e transfusão de sangue ou hemoderivados, hemodiálise ou transplante de órgãos (transmissão iatrogênica). Ter tatuagem ou piercings; ter sido submetido a cirurgias ou recebido injeções com material não descartável; conviver com os vírus B e/ou HIV também fazem parte dos grupos prioritários recomendados para testagem pelo MS ${ }^{9,16} \mathrm{e}$ estavam presentes no estudo.

É importante ressaltar que a lei que impedia a reutilização de seringas e agulhas foi promulgadas em 199622, apesar de produtos descartáveis serem passíveis de importação desde 
a década de 1970. Portanto pessoas nascidas antes da década de 1990 provavelmente receberam injeção com material não descartável, mesmo que não tenham lembrança de tal fato. Assim, durante as entrevistas realizadas pelos investigadores, esta informação pode não ter recebido a importância necessária.

A maior prevalência dos positivos no Distrito Sanitário I do município não pode ser explicada por esse estudo, mas tal achado não deve ser deixado de lado. Merecem investigação adicional a vulnerabilidade social, densidade demográfica, hábitos e condições de vida dos moradores dos bairros da região.

Ainda existem desafios globais e nacionais a serem enfrentados para o alcance desta meta, que tangem dados de vigilância inadequados, cobertura de programas de prevenção limitada, poucas pessoas conhecem seu status de hepatite e têm acesso ao tratamento, medicamentos e diagnósticos são inacessíveis para a maioria, falta abordagem de saúde pública à hepatite e, lideranças e compromissos governamentais desiguais $6,23-25$.

\section{CONCLUSÃo}

O presente estudo possibilitou conhecer a prevalência da Hepatite C no município de Uberaba no estado de Minas Gerais, e a distribuição por década de nascimentos, grupos de risco e dados sócio demográfico e epidemiológico das pessoas testadas com resultado positivo para HCV.

Este estudo apresenta como limitação o fato de estar ligado a um programa que não tinha como meta a sistematização das evidências, mas sim a ampliação do diagnóstico, atendimento às pessoas com resultados positivos, além da capacitação da rede de atenção à saúde.

Entretanto, os resultados da pesquisa apontam resultados relevantes que podem ser utilizados na orientação quantos aos principais grupos a serem testados no município de Uberaba, tais como as pessoas do sexo masculino, residentes no Distrito Sanitário I e nascidas nas décadas de 1950, 1960 e 1970. Tal grupo deve ter a atenção da Rede de Atenção à Saúde redobrada quanto ao agravo Hepatite $\mathrm{C}$.

A partir da análise dos dados retrospectivos do Programa de Ampliação do Diagnóstico da Hepatite $C$ em Uberaba, é possível ressaltar a importância de tais iniciativas. O Programa, que encontrou prevalência geral de 0,73\%, chegando a 2,26\% em determinados Distritos Sanitários, vai ao encontro do Plano para Eliminação da Hepatite C do MS.

Se faz importante capacitar os profissionais da rede de atenção primária sobre a importância da hepatite $\mathrm{C}$, de seu diagnóstico precoce e dos grupos de risco prioritários, além de propiciar a ampliação do acesso ao diagnóstico metas da OMS e do MS.

\section{REFERÊNCIAS}

1. Mbituyumuremyi A, Van Nuil JI, Umuhire J, Mugabo J, Mwumvaneza M, Makuza JD, et al. Controlling hepatitis $\mathrm{C}$ in Rwanda: a framework for a national response. Bull World Health Organ. [Internet]. 2018 [citado em 19 jan 2021]; 96(1):51-8. Disponível em: https://www.ncbi.nlm.nih.gov/pmc/articles/PMC5791867/. DOI: 10.2471/BLT.16.183772

2. Hepatitis C: global ambition, national realities (editorial). Lancet [Internet]. 2016 [citado em 19 jan 2021]; 387(10032):1970.

3. Baptista-González H, Nofal-Nuño VM, Méndez-Sánchez N. Frequency of hepatitis C virus infection in a single institution in Mexico with a focus on birth-cohort population. Ann Hepatol. [Internet]. 2016 [citado em 19 jan 2021]; 15(6):846-52. DOI: 10.5604/16652681.1222100

4. Thrift AP, El-Serag HB, Kanwal F. Global epidemiology and burden of HCV infection and HCVrelated disease. Nat Rev Gastroenterol Hepatol. [Internet]. 2017 [citado em 19 jan 2021]; 14(2):122-32. DOI: $10.1038 /$ nrgastro.2016.176

5. Adland E, Jesuthasan G, Downs, L, Wharton V, Wilde G, McNaughton AL, et al. Hepatitis virus (HCV) diagnosis and access to treatment in a UK cohort. BMC Infect Dis. [Internet]. 2018 [citado em 19 jan 2021]; 18(1):461. DOI: 10.1186/s12879-018-3367-3 
6. World Health Organization. Global health sector strategy on viral hepatitis 2016-2021 [Internet]. Geneva: WHO; 2016 [citado em 9 jan 2020]. Disponível em: https://www.who.int/hepatitis/strategy2016-2021/ghss-hep/en/

7. Akiyama MJ, Kaba F, Rosner Z, Alper H, Holzman RS, MacDonald R. Hepatitis C screening of the "Birth Cohort" (Born 1945-1965) and younger inmates of New York City Jails. Am J Public Health [Internet]. 2016 [citado em 19 jan 2021]; 106(7):1276-7. DOI: 10.2105/AJPH.2016.303163

8. Smith BD, Morgan RL, Beckett GA, Falck-Ytter Y, Holtzman D, Teo CG, et al. Recommendations for the identification of chronic hepatitis $C$ virus infection among persons born during 19451965. MMWR Recomm Rep. [Internet]. 2012 [citado em 19 jan 2021]; 61(RR-4):1-32. Disponível em: https://pubmed.ncbi.nlm.nih.gov/22895429/

9. Ministério da Saúde (Brasil), Secretaria de Vigilância em Saúde,Departamento de Vigilância, Prevenção e controle das IST, do HIV/Aids e das hepatites virais [Internet]. Brasília, DF: Ministério da Saúde; 2019 [citado em 9 jan 2020]. (Plano para eliminação da hepatite C no Brasil). Disponível em: http://www.aids.gov.br/pt-br/pub/2019/plano-para-eliminacao-dahepatite-c-no-brasil

10. Oliveira AC, Bortotti AC, Nunes NN, El Bacha IA, Parise ER. Association between age at diagnosis and degree of liver injury in hepatitis C. Braz J Infect Dis. [Internet]. 2014 [citado em 19 jan 2021]; 18(5):507-11. DOI: https://doi.org/10.1016/j.bjid.2014.04.003

11. Focaccia R, Conceição OJ, Sette Junior H, Sabino E, Bassit L, Nitrini DR, et al. Estimated prevalence of viral hepatitis in the general population of the Municipality of São Paulo, measured by a serologic survey of a stratified, randomized and residence-based population. Braz J Infect Dis. 1998; 2(6):269-84.

12. Pereira LMMB, Martelli CMT, Moreira RC, Merchan-Hamman E, Stein AT, Cardoso MRA, et al. Prevalence and risk factors of Hepatitis C virus infection in Brazil, 2005 through 2009: a cross-sectional study. BMC Infect Dis. [Internet]. 2013 [citado em 19 jan 2021]; 13:60. DOI: 10.1186/1471-2334-13-60

13. Secretaria de Estado da Saúde de Minas Gerais. Estudo de prevalência de base populacional das hepatites virais B e C nas 13 macrorregiões do estado de Minas Gerais. Uma abordagem das doenças e agravos transmissíveis no panorama estadual. Inf Epidemiol. 2014:12-23.

14. Gomide GP, Melo CB, Santos VS, Salge VD, Camargo FC, Pereira GA. Epidemiological survey of hepatitis $C$ in a region considered to have high prevalence: the state of Minas Gerais, Brazil. Rev Soc Bras Med Trop. [Internet]. 2019 Oct 3 [citado em 19 jan 2021]; 52:e20190202. DOI: 10.1590/0037-8682-0202-2019

15. Instituto Brasileiro de Geografia e Estatística. Minas Gerais. Uberaba [Internet]. Rio de Janeiro: IBGE; 2019 [citado em 9 jan 2020]. Disponível em: https://cidades.ibge.gov.br

16. Ministério da Saúde (Brasil), Secretaria de Vigilância em Saúde, Departamento de Vigilância, Prevenção e controle das IST, do HIV/Aids e das hepatites virais [Internet]. Brasília, DF: Ministério da Saúde; 2019 [citado em 9 jan 2020]. (Protocolo clínico e diretrizes terapêuticas para hepatite $\mathrm{C}$ e coinfecções). Disponível em: http://www.aids.gov.br/pt$\mathrm{br} / \mathrm{pub} / 2017 /$ protocolo-clinico-e-diretrizes-terapeuticas-para-hepatite-c-e-coinfeccoes

17. Richard JL, Schaetti C, Basler S, Mäusezahl M. The epidemiology of hepatitis C in Switzerland: trends in notifications, 1988-2015. Swiss Med Wkly. [Internet]. 2018 [citado em 19 jan 2021]; 148:w14619. DOI: 10.4414/smw.2018.14619

18. American Association for the Study of Liver Diseases, Infectious Diseases Society of America. Hepatitis C guidance: AASLD-IDSA recommendations for testing, managing, and treating adults infected with hepatitis C virus. Hepatology [Internet]. 2015 [citado em 19 jan 2021]; 62(3):93254. DOI: $10.1002 /$ hep. 27950

19. Gómez-Escolar Viejo L, García Herola A, Sáez Lloret I, Sánchez Ruano F, Clemente Paulino I, Quílez Ivorra $C$, et al. Screening of hepatitis $C$ virus infection in adult general population in 
Spain. Eur J Gastroenterol Hepatol. [Internet]. 2018 [citado em 19 jan 2021]; 30(9):1077-81. DOI: 10.1097/MEG.0000000000001190

20. Bruggmann P, Berg T, Øvrehus AL, Moreno C, Brandão Mello CE, Roudot-Thoraval F, et al. Historical epidemiology of hepatitis C vírus (HCV) in selected countries. J Viral Hepat. [Internet]. 2014 [citado em 19 jan 2021]; 21(Suppl 1):5-33. DOI: 10.1111/jvh.12247

21. Ministério da Saúde (Brasil), Secretaria de Vigilância em Saúde, Departamento de Doenças de Condições Crônicas e Infecções Sexualmente Transmissíveis. Hepatites virais 2019. Bol Epidemiol. [Internet]. 2019 [citado em 9 jan 2020]; 17(50):1-71. Disponível em: http://www.aids.gov.br/pt-br/pub/2019/boletim-epidemiologico-de-hepatites-virais-2019 22. Presidência da República (Brasil), Casa Civil, Subchefia para Assuntos Jurídicos. Lei no 9.273, de 3 de maio de 1996. Torna obrigatória a inclusão de dispositivo de segurança que impeça a reutilização das seringas descartáveis. Diário Oficial União [Internet]. 1996 [citado em 19 jan 2021]; 1:7625. Disponível em: https://www2.camara.leg.br/legin/fed/lei/1996/lei-9273-3maio-1996-372353-publicacaooriginal-1-pl.html

23. Harm Reduction International. The global state of harm reduction 2018 [Internet]. $6^{\text {thed. }}$ London: Phoenix Media Group; 2018 [citado em 17 jan 2020]. Disponível em: https://www.hri.global/global-state-harm-reduction-2018

24. Dore GJ, Ward J, Thursz M. Hepatitis C disease burden and strategies to manage the burden (Guest Editors Mark Thursz, Gregory Dore and John Ward). J Viral Hepat. [Internet]. 2014 [citado em 19 jan 2021]; 21(Suppl 1):1-4. DOI: 10.1111/jvh.12253

25. Aghemo A, Dore GJ, Hatzakis A, Wedemeyer H, Razavi H. Estimating HCV disease burden volume 3 (editorial). J Viral Hepat. [Internet]. 2015 [citado em 19 jan 2021];22(Suppl 4):1-3. DOI: $10.1111 /$ jvh.12473

Editora Associada: Vania Del Arco Paschoal

\section{CONTRIBUIÇõES}

Cristina Cunha Hueb Barata Oliveira e Geisa Perez Medina Gomide contribuíram na concepção, coleta e análise dos dados, redação e revisão. Gilberto Araújo Pereira e Rodrigo Juliano Molina participaram da concepção, coleta e análise dos dados.

\section{Como citar este artigo (Vancouver)}

Gomide GPM, Molina RJ, Pereira GA, Oliveira CCHB. Diagnóstico precoce da hepatite C pela atenção primária à saúde. REFACS [Internet]. 2021 [citado em inserir dia, mês e ano de acesso]; 9(Supl. 1):271-280. Disponível em: inserir link de acesso. DOI: inserir link do DOI

\section{Como citar este artigo (ABNT)}

GOMIDE, G. P. M.; MOLINA, R. J.; PEREIRA, G. A.; OLIVEIRA, C. C. H. B. Diagnóstico precoce da hepatite $C$ pela atenção primária à saúde. REFACS, Uberaba, MG, v. 9, p. 271-280, 2021. Supl. 1. DOI: inserir link do DOI. Disponível em: inserir link de acesso. Acesso em: inserir dia, mês e ano de acesso.

\section{Como citar este artigo (APA)}

Gomide, G.P.M., Molina, R.J., Pereira, G.A., \& Oliveira, C.C.H.B. (2021). Diagnóstico precoce da hepatite $C$ pela atenção primária à saúde. REFACS, 9(Supl. 1), 271-280. Recuperado em inserir dia, mês e ano de acesso de inserir link de acesso. DOI: inserir link do DOI. 